\title{
Father-toddler communication in low-income families: The role of paternal education and depressive symptoms
}

\section{Citation}

Malin, Jenessa L., Elizabeth Karberg, Natasha J. Cabrera, Meredith Rowe, Tonia Cristaforo, and Catherine S. Tamis-LeMonda. 2012. "Father-toddler Communication in Low-Income Families: The Role of Paternal Education and Depressive Symptoms." Family Science 3 (3-4) (July): 155163.

\section{Published Version}

doi:10.1080/19424620.2012.779423

\section{Permanent link}

http://nrs.harvard.edu/urn-3:HUL.InstRepos:13041197

\section{Terms of Use}

This article was downloaded from Harvard University's DASH repository, and is made available under the terms and conditions applicable to Other Posted Material, as set forth at http:// nrs.harvard.edu/urn-3:HUL.InstRepos:dash.current.terms-of-use\#LAA

\section{Share Your Story}

The Harvard community has made this article openly available.

Please share how this access benefits you. Submit a story.

Accessibility 


\title{
Father-toddler communication in low-income families: The role of paternal education and depressive symptoms
}

\author{
Jenessa L. Malin ${ }^{\mathrm{a} *}$, Elizabeth Karberg ${ }^{\mathrm{a}}$, Natasha J. Cabrera ${ }^{\mathrm{a}}$, Meredith Rowe ${ }^{\mathrm{a}}$, Tonia Cristaforo ${ }^{\mathrm{b}}$ \\ and Catherine S. Tamis-LeMonda ${ }^{\mathrm{c}}$ \\ ${ }^{a}$ Department of Human Development and Quantitative Methodology, University of Maryland, College Park, USA; ${ }^{b}$ University Settlement

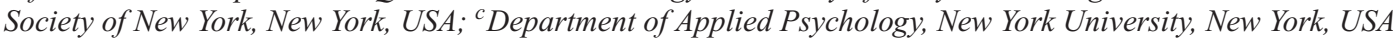

(Received 23 October 2012; final version received 7 March 2013)

\begin{abstract}
Using data from a racially and ethnically diverse sample of low-income fathers and their 2-year-old children who participated in the Early Head Start Research Evaluation Project $(n=80)$, the current study explored the association among paternal depressive symptoms and level of education, fathers' language to their children, and children's language skills. There were three main findings. First, there was large variability in the quality and quantity of language used during linguistic interactions between low-income fathers and their toddlers. Second, fathers with higher levels of education had children who spoke more (i.e. utterances) and had more diverse vocabularies (i.e. word types) than fathers with lower levels of education. However, fathers with more depressive symptoms had children with less grammatically complex language (i.e. smaller MLUs) than fathers with fewer depressive symptoms. Third, direct effects between fathers' depressive symptoms and level of education and children's language outcomes were partially mediated by fathers' quantity and quality of language.
\end{abstract}

Keywords: fathers; toddlers; language; depression; low income

\section{Introduction}

Research on fathers' contributions to their children's outcomes has recently focused on early language development (Tamis-LeMonda, Cristofaro, Rodriguez, \& Bornstein, 2006). Emerging findings show that father's language (e.g. vocabulary, complexity, questions, and pragmatics) is linked with children's language, specifically complexity and vocabulary (Pancsofar \& Vernon-Feagans, 2006; Pancsofar, Vernon-Feagans, \& The Family Life Project Investigators, 2010; Tamis-LeMonda et al., 2006). These findings suggest that fathers' linguistic interchanges with their children are directly related to children's language skills, which are critical for school readiness. This is particularly noteworthy for children living in low-income families because they are more likely to have slower vocabulary growth than their middle- and high-income counterparts (e.g. Arriaga, Fenson, Cronan, \& Pethick, 1998) and these growth rates are highly predictive of kindergarten language abilities (Rowe, Raudenbush, \& Goldin-Meadow, 2012). Thus, promoting positive father linguistic interactions might contribute to low-income children's language development and ultimate school achievement.

However, research on how fathers contribute to their children's language development is still in its infancy. Among low-income families, in which children are most at risk for school difficulties, there is much to learn about the quantity and quality of fathers' linguistic interchanges with their children as well as the factors that promote such interchanges and predict children's language skills. This is particularly important during early childhood, where children build foundational blocks for language growth and development. In this study, we seek answers to the following research questions: (1) How much variability is there in the quantity and quality of language used by low-income fathers and their children during a linguistic interaction? (2) Do fathers' levels of education and depressive symptoms influence children's quantity (i.e. total utterances) and quality (i.e. vocabulary diversity and grammatical complexity) of language? And (3) Do quantity and quality of fathers' language mediate the association between fathers' depressive symptoms and educational attainment and children's language skills?

\section{Theoretical framework}

Research has shown that infants attend to surrounding verbal and nonverbal communications and forge relationships through responsive interactions with their caregivers (Risley \& Hart, 2006). Caregivers and others support children's language learning by providing stimulating and challenging interchanges that are attuned to children's developmental needs (Bruner, 1981). The present study

*Corresponding author. Email: jlmalin@umd.edu 
is framed by a social-interactionist approach to language learning (Bruner, 1981; Vygotsky, 2000) which posits that children learn language from interacting with others, particularly parents, during the early childhood years. Fathers support children's language by providing stimulating and challenging interchanges that are attuned to children's developmental needs. Through the direct interactions fathers have with their children, they can promote language development by using words to describe objects, asking questions, and encouraging children to respond. Both the amount (i.e. utterances) and quality (i.e. types and grammatical complexity) of language that fathers use with their children during interactions are important predictors of children's language skills (Raikes et al., 2006; Rodriguez \& Tamis-LeMonda, 2011).

There is, however, wide variability in the amount and quality of language that fathers use in their linguistic interactions with their children. Previous work on parents' talk to their children, most of it conducted with mothers, suggests that psychological characteristics, such as depression, influence the language that parents offer children. For example, depressed mothers from low-income families are found to talk less to their children than their nondepressed counterparts (Rowe, Pan, \& Ayoub, 2005). One study reported that fathers with higher reports of depressive symptoms have children with less advanced vocabularies (Paulson, Keefe, \& Leiferman, 2009). Given that low-income fathers are more likely to exhibit depressive symptoms than other fathers (Zimmerman \& Katon, 2005), paternal depressive symptoms might be an important source of variation in the amount and quality of language low-income fathers use with their children, which is directly related to children's language skills.

Another potential source of variability in how fathers talk to their children is education. Research shows consistent positive relations between maternal education and maternal talk with children (see Hoff, 2006 for a review). Previous research has found that fathers with higher levels of education have more advanced vocabularies than fathers with lower levels of education (Pancsofar \& Vernon-Feagans, 2006), which has been found to be linked with more advanced language skills in children (Cabrera, Shannon, \& Tamis-LeMonda, 2007). Thus, in this study, we examine how father's depressive symptoms and levels of education are related to fathers' and children's language skills.

\section{Father-child linguistic interactions: how fathers talk to their children}

Overall, fathers engage with their children in multiple ways including caregiving, physical play, and to a lesser extent, in cognitive stimulating activities such as reading and telling stories (Cabrera, Hofferth, \& Chae, 2011;
Pleck \& Masciadrelli, 2004). As children develop language, father's linguistic interchanges with their children during play and other activities play a central role in promoting language skills. Although both mothers and fathers serve as linguistic partners for children, increasing evidence suggests that these communicative interactions might be different for mothers and fathers. Rowe, Coker, and Pan (2004) compared the communicative experiences that mothers and fathers offered their toddlers during play and book reading activities. They found that fathers posed more wh-questions and explicit requests for clarification to their children and, as a consequence, toddlers used more complex speech with their fathers than with their mothers (Rowe et al., 2004). Prior research has also found that fathers are more likely than mothers to use language that conversationally challenges a child's linguistic skills (Ely, Gleason, Narasimhan, \& McCabe, 1995; Tomasello, Conti-Ramsden, \& Ewert, 1990).

\section{Linking fathers' language skills to children's language skills}

Research has shown that father-child linguistic interactions provide a unique and important basis for the development of children's language skills (Ely et al., 1995; Rowe et al., 2004). In terms of fathers' quality of talk with their children, researchers have found that fathers' mean length of utterance (MLU) uniquely predicts children's vocabulary diversity (types) and MLU (Rowe et al., 2004). Additionally, when examined together, fathers', but not mothers', communicative diversity predicted children's communicative diversity (Pancsofar et al., 2010). In a study of African American families, after controlling for paternal education and maternal language, fathers were found to contribute uniquely to their children's expressive language through verbal affection and vocalizations, even though mothers' quantity of language was greater than fathers' quantity of language (Roopnarine, Fouts, Lamb, \& LewisElligan, 2005). Recent studies with low-income rural families show that the association between father vocabulary production and child language holds when maternal language is controlled (Pancsofar \& Vernon-Feagans, 2006; Pancsofar et al., 2010). In summary, the quality and quantity of fathers' speech, measured in multiple ways, is uniquely related to children's language skills.

\section{Paternal education and depressive symptoms: links to parents' and children's language skills}

Compared to parents from higher socioeconomic status (SES), low SES parents are more likely to have children with limited vocabulary (Hart \& Risley, 1995; Pancsofar et al., 2010). On average, low SES mothers talk less, use smaller vocabularies, and ask fewer questions to their children than higher SES mothers (Hart \& Risley, 1995; 
Hoff, Laursen, \& Tardif, 2002), and this is related to smaller average vocabularies for the children from lower SES families (Hart \& Risley, 1995; Hoff, 2003). In particular, mothers with higher levels of education are more likely to engage in linguistic interaction with their infants and speak more words than less educated mothers. For example, on average, middle-class 2-year-old children hear roughly twice as many words over the course of a week than low-income 2-year-old children (Hoff, 2006). Research with fathers has also shown that father-child linguistic interactions are influenced by socioeconomic factors including paternal education (Duursma, Pan, \& Raikes, 2008).

The links between SES and children's language skills are well documented, but the mechanisms through which SES affects child language are less studied, particularly in regard to fathers. The current study addresses this gap by examining whether fathers' language skills mediate the association between father's education and children's language skills. We expect paternal education to be linked to paternal quantity and quality of language in a similar way that maternal education is associated with maternal quantity and quality of language. Thus, we hypothesize that, on average, fathers with fewer years of education will have children with less advanced language skills because they speak less and use less diverse and sophisticated language with their children.

Paternal mental health (i.e. depressive symptoms) may also directly influence children's language skills (Mensah \& Kiernan, 2010). Most research on the contributions of parental depression to children's outcomes has been conducted with mothers; thus little is known about how paternal depression might be linked to children's outcomes. Some emerging research has specifically suggested that high levels of paternal depression may put children at risk for poor language skills (Mensah \& Kiernan, 2010; Paulson et al., 2009). For example, Mensah and Kiernan (2010) found that high levels of psychological distress among both mothers and fathers were linked to children's lower attainment in communication, language, and literacy. Based on the review of the literature, we hypothesize that fathers with more depressive symptoms will have children with less advanced language skills than fathers with fewer depressive symptoms.

The mechanism by which paternal depression influences children's vocabulary is relatively unexamined. One possible mechanism might be through the amount and quality of fathers' language. Fathers who exhibit depressive symptoms might speak less and their speech might be less diverse and less complex, on average, than fathers with fewer depressive symptoms (Ramchandani, Stein, Evans, \& O'Connor, 2005). We thus hypothesize that fathers with more depressive symptoms will have children with lower quality and quantity of language because they speak less and use low quality language when interacting with their children than fathers with fewer depressive symptoms.

\section{Present study}

The current study seeks to extend the existing literature on father engagement and early language development by examining the associations between father education and mental health, fathers' talk with their children, and children's language skills.

We hypothesize that, on average, fathers with higher levels of depressive symptoms and lower levels of education will have children who use language with lower quantity (fewer utterances) and quality (less vocabulary diversity and less grammatical complexity) of language. Further, we hypothesize that the association between paternal depressive symptoms and educational level and child language skills will be mediated by the amount and quality of father's language.

\section{Method \\ Data source}

Data used in this study were obtained from Healthy Attachment Promotion for Parents and Infants (HAPPI) and from the Father Involvement with Toddlers Substudy (FITS) of the Early Head Start Research Evaluation Project (EHSREP). The HAPPI study followed the same methodology and the same measures as the FITS. Children participating in the HAPPI project were recruited from Early Head Start (EHS) Centers in the Washington, DC area (see Mitchell \& Cabrera, 2009 for additional information on recruitment and study characteristics) and children participating in the FITS study were recruited from EHS sites across the US (see Boller et al., 2006 for additional information on recruitment and study characteristics). All participating families in both studies were eligible for EHS services based on family income (at or below the federal poverty level), as EHS is a federal program that provides services for low-income families (see Raikes \& Love, 2002). From the FITS sample, we selected a subsample of fathers with available videotaped father-child observational data at the 24-month data collection wave. In general, fathers who participated in both studies were more likely to have completed more years of education, and to be employed than families in which fathers did not participate (see Cabrera et al., 2004; see Mitchell \& Cabrera, 2009 for more detailed analysis of selection bias).

\section{Participants}

Participants were 80 fathers and their toddlers from low-income, African American $(n=60)$ and Latino $(n=20)$ families who participated in HAPPI and FITS. 
The majority of the fathers in the sample, $73.7 \%$, had at least a high school education. All fathers identified English as their dominant language and spoke English during the videotaped linguistic interactions; $53.8 \%$ of children were female.

\section{Procedures}

Data collection in FITS and HAPPI studies was conducted in the same way and included child assessments, mother and father interviews, and home visits during which videotaped observations of parent-child interactions were obtained. At 24 months, father visits involved interviews and videotaped sequences of parent-child play. All interviews, videotaped interactions, and child assessments were completed in the family's primary language. Father-child interactions were videotaped during three activities, including 10 minutes of semi-structured free play, which was the focus of the present investigation. During free play, toys were presented to parents in three separate bags (toys: \#1, a book; \#2, a pizza set and telephone; and \#3, a farm with farm animals). All toys were designed to be age appropriate and stimulate talk and play between father and child. Each parent was asked to sit on a mat with his/her child, try to ignore the camera, and to do whatever felt most natural. They were instructed to only play with the toys from the three bags and to start with bag \#1, move on to bag \#2, and finish with bag \#3. They were told that they could divide up the 10 minutes as they liked.

\section{Measures}

The measures for this study were selected for their psychometric properties and applicability to low-income populations.

\section{Father and child language measures}

Transcriptions of the 10-minute father-child, semistructured play interactions were done verbatim from videotapes using Codes for the Analysis of Human Language (CHAT) conventions of the Child Language Data Exchange System (CHILDES; MacWhinney, 2000). All speech of both father and child were transcribed at the utterance unit level. A second, reliable, transcriber verified each transcript for accuracy. The father-child videotaped interactions were then coded to determine both the quality and amount of language spoken by both fathers and their children. Naturally observed speech samples of parentchild interactions have proven particularly valuable when studying early language development (Pan, Rowe, Spier, \& Tamis-LeMonda, 2004).

Automated analyses of the transcripts using the CHILDES software provided values for father and child speech measures. Specifically, we calculated quantity of speech (i.e. total number of utterances produced), and quality of speech, including vocabulary diversity (i.e. number of different word types produced), and grammatical complexity (i.e. MLU).

\section{Paternal depressive symptoms}

Paternal depressive symptoms were measured using the Center for Epidemiological Studies Depression Scale (CES-D; Radloff, 1977) which comprised 20 self-report items about the absence or presence of negative thoughts, feelings, and behaviors during the prior week. Sample items include 'How often in the past week did you ... feel depressed? feel lonely?, have crying spells?, and have difficulty sleeping?' Items were rated on a 4-point Likert scale ( $0=$ rarely or never to $4=$ most or all days). Scores above 16 typically indicate mild depressive symptomology and scores above 27 typically indicate moderate/severe depressive symptomology.

\section{Paternal level of education}

Fathers indicated years of education, which was then classified into 1 of 3 groups: less than a high school diploma, high school diploma or equivalent, or more than a high school diploma.

\section{Control variables}

In addition to the main variables of interest, we used other child and family characteristics to control for possible biasing factors. Specifically, child age (in months) at the time of the father-child interaction and father ethnicity were used as control variables.

\section{Results}

\section{Analytic strategy}

To address our research questions, we first present descriptive statistics for all measures. We then discuss correlations to determine (1) associations between father background measures (e.g. education and depression) and father and child language use and (2) relations between father and child language use. Finally, we conduct multiple regression analysis to determine simultaneous effects of background measures and father's language production on child's language outcomes, and to assess whether fathers' quality and quantity of language mediates the relations between background variables and child language outcomes. The data for the analysis include demographic information, father questionnaire responses, and videotaped father-child interactions, all from the 24-month data collection wave. The children's age varied from 18 to 35 months, with a mean age of 26 months. 


\section{Descriptive statistics}

Our first research question was descriptive. Means and standard deviations for all measures are presented in Table 1. We found large variability in the quantity and quality of language used in semi-structured linguistic interactions between low-income African American and Latino fathers and their toddlers. For example, the average number of father utterances was 284.6 but there was a wide range from 12 to 816 . The average number of father word types was 158.6 (range $=43$ to 254 ), and the average father MLU was 3.1 (range $=1.5$ to 4.1 ). Overall, scores of paternal depressive symptoms averaged 17.23 (range $=1$ to 48.42). Most fathers in our sample reported having completed high school $(n=44) ; 15$ fathers reported less than a high school degree and 21 fathers reported more than a high school degree. The children in our sample also showed wide variability in their language; the average number of utterances was 61.5 (range $=2$ to 157 ), the average number of word types (i.e. vocabulary diversity) was 45.04 (range $=2$ to 102 ), and the average MLU (i.e. grammatical complexity) was 1.77 (range $=1$ to 3 ).

\section{Associations between background measures, father's language, and child's language}

Correlations are presented in Table 2. Bivariate correlations showed that fathers with higher levels of education and lower levels of depressive symptoms spoke more and used

Table 1. Descriptive statistics $(n=80)$.

\begin{tabular}{lccc}
\hline Variable & $n$ & $\%$ & $M(\mathrm{SD})$ \\
\hline Child gender & & & \\
Male & 37 & 46.2 & \\
Female & 43 & 53.8 & $26.34(3.38)$ \\
Child age (months) & 80 & 100 & \\
Mother years of school & & & \\
$\quad \quad$ HS degree & 27 & 33.8 & \\
HS degree & 28 & 35.0 & \\
$\quad$ > HS degree & 25 & 31.3 & \\
Father years of school & & & \\
$\quad$ <HS degree & 15 & 18.7 & \\
HS degree & 44 & 55.0 & \\
$\quad$ > HS degree & 21 & 26.3 & \\
Father ethnicity & & & \\
African American & 60 & 75.0 & \\
Latino & 20 & 25.0 & \\
Father depression score & 80 & 100 & $17.23(12.80)$ \\
Father \# of utterances & 80 & 100 & $284.59(171.64)$ \\
Father language quality & 80 & 100 & $-.006(.998)$ \\
Child \# of utterances & 80 & 100 & $61.53(35.19)$ \\
Child MLU & 80 & 100 & $1.77(.51)$ \\
Child types & 80 & 100 & $45.04(24.19)$ \\
\hline
\end{tabular}

Notes: $<$ HS degree, completed less than high school/did not complete high school; HS degree, high school degree or equivalent (e.g. GED); > HS degree, some college or college/graduate/technical degree; MLU, grammatical complexity; types, vocabulary diversity. Father's language quality is a composite measure of father's grammatical complexity and father's vocabulary diversity. higher quality language with their children. Additionally, paternal education was positively correlated with child utterances and types, whereas paternal depressive symptoms were negatively correlated with child grammatical complexity. All of the child language measures were positively correlated with one another. Father grammatical complexity and vocabulary diversity were highly correlated, whereas father quantity of utterances was not correlated with father quality of language measures (grammatical complexity and vocabulary diversity).

Because fathers' grammatical complexity and vocabulary diversity were highly correlated, we created a composite of father's language quality using Principal Components Analysis. The first component weighted the two father language variables equally and explained $72 \%$ of the original variance. The composite had a mean of 0 and a 1 . Fathers who scored high on the composite used a diverse vocabulary and more complex utterances than fathers who scored low on the composite. Father's language quantity was kept as a distinct measure of father's language.

\section{Regression results}

To further address our research questions, we conducted a series of multiple regression analyses to examine simultaneous effects of paternal background characteristics (education and depressive symptoms) and fathers' quality and quantity of language on children's language skills. We ran three regression analyses for the three child language outcomes: (1) quantity of speech (total number of utterances), (2) vocabulary diversity (word types), and (3) grammatical complexity (MLU). In each analysis, model 1 included our control variables, child age and father ethnicity. Model 2 assessed the direct effects of paternal depressive symptoms and father level of education on child language controlling for father ethnicity and child age. Using Baron and Kenny's (1986) method for discerning mediation, model 3 assessed the meditational effect of father's language (quantity and quality) on the association between father depression and father level of education with child language (Baron \& Kenny, 1986). The results of these analyses are presented in Tables 3-5.

\section{Predicting the quantity of child's language (total number of utterances)}

Table 3 shows that controlling for ethnicity and child age $(p<.05)$, fathers with higher levels of education had children who spoke more (total utterances) $\left(\beta^{*}=.233\right.$, $t(75)=2.282, p=.025)$ than fathers with lower levels of education. Fathers' level of education accounted for $5 \%$ of the variance in total child utterances (result not shown in table). Paternal depressive symptoms did not predict children's total number of utterances, nor did father quantity or quality of talk. 
Table 2. Intercorrelations of model variables.

\begin{tabular}{|c|c|c|c|c|c|c|c|c|c|c|c|c|}
\hline & 1 & 2 & 3 & 4 & 5 & 6 & 7 & 8 & 9 & 10 & 11 & 12 \\
\hline 1. Child gender & 1 & & & & & & & & & & & \\
\hline 2. Child age & $-.239^{*}$ & 1 & & & & & & & & & & \\
\hline 3. Maternal ed. & .060 & -.039 & 1 & & & & & & & & & \\
\hline 4. Paternal ed. & .093 & .128 & .024 & 1 & & & & & & & & \\
\hline 5. Father ethnicity & .043 & -.024 & -.090 & .059 & 1 & & & & & & & \\
\hline 6. Depression & .096 & $-.274^{*}$ & -.180 & -.139 & -.129 & 1 & & & & & & \\
\hline 7. Father MLU & -.040 & -.022 & .034 & $.236^{*}$ & .045 & -.128 & 1 & & & & & \\
\hline 8. Father types & .135 & .107 & -.015 & $.240^{*}$ & -.013 & $-.290^{* *}$ & $.451^{* *}$ & 1 & & & & \\
\hline 9. Father utterances & .074 & -.002 & $.254^{*}$ & $-.227^{*}$ & -.252 & $-.229^{*}$ & $.451^{* *}$ & $.365^{* *}$ & 1 & & & \\
\hline 10. Child MLU & -.165 & .188 & .188 & .018 & -.205 & $-.332^{* *}$ & .204 & .086 & $.364^{* *}$ & 1 & & \\
\hline 11. Child types & -.177 & $.484^{* *}$ & -.089 & $.404^{* *}$ & -.021 & -.216 & $.397^{* *}$ & $.327^{* *}$ & -.123 & $.256^{*}$ & 1 & \\
\hline 12. Child utt. & -.120 & $.425^{* *}$ & .019 & $.290^{* *}$ & .036 & -.181 & $.235^{*}$ & .213 & .079 & $.299^{* *}$ & $.804^{* *}$ & 1 \\
\hline
\end{tabular}

Notes: ${ }^{*} p<.05^{* *} p<.01$.

Ed., educational level; depression, paternal depressive symptoms; MLU, grammatical complexity; types, vocabulary diversity; Utt., total utterances.

Table 3. Multiple regression model predicting child utterances $(n=80)$.

\begin{tabular}{|c|c|c|c|c|c|c|c|c|c|}
\hline & \multicolumn{3}{|c|}{ Model 1} & \multicolumn{3}{|c|}{ Model 2} & \multicolumn{3}{|c|}{ Model 3} \\
\hline & $B$ & SE & $\beta$ & $B$ & $\mathrm{SE}$ & $\beta$ & $B$ & SE & $\beta$ \\
\hline Child age & 4.429 & 1.072 & $.426^{*}$ & 4.000 & 1.096 & $.385^{*}$ & 4.170 & 1.080 & $.401^{*}$ \\
\hline Father ethnicity & 3.723 & 8.322 & .046 & 2.121 & 8.227 & .026 & 5.521 & 8.462 & .068 \\
\hline Father education & & & & 11.062 & 4.847 & $.233^{*}$ & 10.553 & 5.155 & $.223^{*}$ \\
\hline Father depression & & & & -.110 & .292 & -.040 & .114 & .307 & .041 \\
\hline Father utterances & & & & & & & .027 & .023 & .134 \\
\hline Father quality & & & & & & & 6.052 & 3.773 & .172 \\
\hline
\end{tabular}

Notes: ${ }^{*} p<.05$

1. $R^{2}=.183, F(2,77)=8.600, p<.001$.

2. $R^{2}=.239, F(4,75)=5.895, p<.001$.

3. $R^{2}=.285, F(5,74)=4.860, p<.001$.

Table 4. Multiple regression model predicting child types $(n=80)$.

\begin{tabular}{|c|c|c|c|c|c|c|c|c|c|}
\hline & \multicolumn{3}{|c|}{ Model 1} & \multicolumn{3}{|c|}{ Model 2} & \multicolumn{3}{|c|}{ Model 3} \\
\hline & $B$ & $\mathrm{SE}$ & $\beta$ & $B$ & SE & $\beta$ & $B$ & SE & $\beta$ \\
\hline Child age & 3.456 & .713 & $.483^{*}$ & 3.024 & .693 & $.423^{*}$ & 3.073 & .639 & $.430^{*}$ \\
\hline Father ethnicity & -.540 & 5.539 & -.010 & -2.156 & 5.200 & -.039 & -3.851 & 5.003 & -.069 \\
\hline Father education & & & & 11.216 & 3.064 & $.344^{*}$ & 7.106 & 3.048 & $.218^{*}$ \\
\hline Father depression & & & & -.109 & .185 & -.058 & -.042 & .182 & -.022 \\
\hline Father utterances & & & & & & & -.020 & .014 & -.143 \\
\hline Father quality & & & & & & & 8.653 & 2.231 & $.357^{*}$ \\
\hline
\end{tabular}

Notes: ${ }^{*} p<.05$.

1. $R^{2}=.234, F(2,77)=11.764, p<.001$.

2. $R^{2}=.357, F(4,75)=10.409, p<.001$.

3. $R^{2}=.472, F(6,73)=10.857, p<.001$.

\section{Predicting diversity of children's vocabulary (number of different word types)}

Table 4 shows that controlling for ethnicity and child age $(p<.05)$, fathers with higher levels of education had children with more vocabulary diversity $\left(\beta^{*}=.344\right.$, $t(75)=3.661, p<.001)$. Fathers' level of education accounted for $11 \%$ of the variance in child vocabulary diversity (result not shown in table). A mediation analysis revealed that father's language quality partially mediated the association between fathers' level of education and children's vocabulary diversity $\left(\beta^{*}=.357, t(73)=3.879\right.$, $\left.p<.001, R^{2}=.109\right)\left(R^{2}\right.$ not in table). That is, fathers with higher levels of education had children with more vocabulary diversity because fathers used more complex and diverse language when interacting with their children. Paternal depressive symptoms did not predict children's vocabulary diversity, nor did quantity of paternal utterances. 
Table 5. Multiple regression model predicting child MLU $(n=80)$.

\begin{tabular}{|c|c|c|c|c|c|c|c|c|c|}
\hline & \multicolumn{3}{|c|}{ Model 1} & \multicolumn{3}{|c|}{ Model 2} & \multicolumn{3}{|c|}{ Model 3} \\
\hline & $B$ & $S E$ & $\beta$ & $B$ & $S E$ & $\beta$ & $B$ & $S E$ & $\beta$ \\
\hline Child age & .028 & .017 & .183 & .014 & .017 & .091 & .017 & .016 & .111 \\
\hline Father ethnicity & -.236 & .129 & -.201 & -.289 & .124 & $-.246^{*}$ & -.201 & .127 & -.171 \\
\hline Father education & & & & -.018 & .073 & -.026 & .014 & .077 & .021 \\
\hline Father depression & & & & -.014 & .004 & $-.342^{*}$ & -.010 & .005 & $-.244^{*}$ \\
\hline Father utterances & & & & & & & .001 & .000 & $.261^{*}$ \\
\hline Father quality & & & & & & & .034 & .056 & .067 \\
\hline
\end{tabular}

Notes: ${ }^{*} p<.05$.

1. $R^{2}=.076, F(2,77)=3.147, p=.049$.

2. $R^{2}=.181, F(4,75)=4.135, p=.004$.

3. $R^{2}=.244, F(6,73)=3.922, p=.002$.

\section{Predicting grammatical complexity of child speech}

\section{(MLUs)}

Table 5 shows that controlling for ethnicity and child age, fathers with more depressive symptoms had children with smaller MLUs, an indicator of grammatically complex language $\left(\beta^{*}=-.342, t(75)=-3.102, p=.003\right)$ than fathers with fewer depressive symptoms. Father depressive symptoms accounted for roughly $5 \%$ of the variance in child MLUs (result not in table). A mediation analysis revealed that father quantity of utterances partially mediated the association between paternal depressive symptoms and child MLUs $(\beta=-.244, t(71)=-2.126, p=.037$, $\left.R^{2}=.047\right)\left(R^{2}\right.$ not in table). That is, fathers reporting more depressive symptoms had children with less grammatically complex speech because fathers used fewer utterances during interactions with their children.

\section{Discussion}

This study contributes to the limited literature on fathers' contributions to their children's language skills by examining the direct and indirect pathways by which fathers' depressive symptoms and level of education are associated with children's quality (grammatical complexity and vocabulary diversity) and quantity (number of total utterances) of language.

Given the paucity of research on how much language fathers use with their toddlers, our first research question was descriptive. Our findings show large variability in fathers' and toddlers' communication in the context of a semi-structured free play activity. That is, fathers and children exhibited wide variability in terms of grammatical complexity, vocabulary diversity, and in total number of utterances. These findings suggest that while some lowincome children are at risk for language difficulties, others, as shown in this study, may not be. Many children in our study are hearing paternal language production of much higher quantity and quality than other children in this sample, which can place them on a more advantageous track.
This finding offers insight into the variability found in children's language skills in low-income families who are generally believed to hear roughly half of the words over the course of a week than middle-class 2-year-old children hear (Hoff, 2006).

The second and third aims of our study were to understand the sources of variability in fathers' talk to children we examined two factors, namely paternal depressive symptoms and paternal levels of education. We also examined the mechanism by which father factors were linked to the quantity and quality of children's language.

Based on the literature review that depressive symptoms are important indicators of the quantity and quality of fathers' talk to children (Bagner, Pettit, Lewinsohn, \& Seeley, 2010; Mensah \& Kiernan, 2010), we examined the direct associations between fathers' depressive symptoms and children's language skills. In our sample, fathers reported an average level of depressive symptoms. Even so, we found that fathers who reported higher levels of depressive symptoms had children with lower quality of language, specifically lower grammatical complexity (MLUs). Depressive symptoms were not related to the number of word types or total number of utterances children produced. This finding is consistent with an emerging literature that has identified paternal depression as a risk factor for children (Mensah \& Kiernan, 2010; Paulson et al., 2009; Ramchandani et al., 2005) but goes beyond it by suggesting that children whose fathers report a high number of depressive symptoms may exhibit specific difficulties related to one aspect of quality of language. One possible explanation for finding associations with complexity but not with diversity of language might be the age of our children. Given that speech samples were measured when children were only 24 months of age, differences in grammatical complexity of language may be a more accurate indicator of linguistic capability, as it is tapping into a more difficult skill, at this age than differences in quantity or diversity of language. Nevertheless, this is a fruitful direction for future research. 
As hypothesized, we found that father's total number of utterances mediated the association between paternal depressive symptoms and children's grammatical complexity. That is, fathers who reported more depressive symptoms had children with less complex utterances (MLUs) partially because fathers spoke less to their children. It is noteworthy that depressive symptoms operate through quantity, not quality, of father's talk. This finding is consistent with other research that shows that depressed mothers are more withdrawn and less talkative than nondepressed parents (Rowe et al., 2005). Moreover, this finding extends prior findings showing that father's mental health has a negative influence on the quality of father-child interactions (Cummings, Keller, \& Davies, 2005) by showing that it also has a negative effect on how much fathers talk to their children. Specifically, paternal depressive symptoms are a risk factor for children's grammatical complexity of language.

We also examined how much of the variability in children's language skills was related to fathers' level of education. Consistent with prior studies (e.g. Hart \& Risley, 1995), our findings show that fathers with higher levels of education have children who not only talk more, but also use more diverse vocabulary. Although research has shown quite robustly that parents' education is strongly predictive of children's language skills, the mechanism by which this occurs is less clear. In this study, we examined how the quantity and quality of fathers' language mediated this association. We found that paternal education operated through fathers' quality of language. That is, fathers had children with more advanced language skills because they used higher quality language when interacting with their children (Pancsofar \& Vernon-Feagans, 2006; Pancsofar et al., 2010; Tamis-LeMonda et al., 2006). Previous research with middle-class mothers has found that mothers with higher levels of education have toddlers with higher expressive language skills because they are using better quality language during interactions with their children (Hoff, 2006). Taken together, these findings suggest that increasing the educational attainment and addressing the mental health of fathers may be a cost-effective intervention to reduce the risk of low-income children developing language difficulties.

This study had several limitations. First, given the difficulty in recruiting low-income populations to participate in research, our sample is small and select thus is not representative of low-income minority fathers in general. Moreover, we do not have comparable measures of language from mothers. Thus, we were not able to consider the both parents' quality and quantity of language to their children. Additionally, both father and child language skills were assessed from one father-child interaction. Finally, all data included in this study were measured at the same time, thus all analyses are concurrent rather than longitudinal. We cannot speak to children's language change over time but rather understand the cross-sectional influences contributing to their linguistic skills.

Despite these limitations, our study contributes to the literature in important ways. First, we provide evidence of large variability in the quantity and quality of fathers' and toddlers' communication in low-income families. Many children in economically struggling families may do well in school because their parents engage them in rich linguistic interchanges that foster high quality of language. Second, our findings also show that paternal depressive symptoms and low levels of education explain the variability in low-income fathers' talk to their children. Future research should explore how both maternal and paternal mental health and education uniquely and additively contribute to children's language development. Moreover, our findings show that fathers' language quality, in particular complexity, helps explain why father's levels of education are linked to children's language skills and that fathers' quantity of language help explain why paternal depressive symptoms are negatively linked to children's language. These findings have important implications for practitioners and policymakers and suggest that fathers are an untapped source contributing to their children's language skills. Public policy campaigns aimed at encouraging fathers to talk to their children often might be a cost-effective way to reduce some disparities in low-income children's language skills, which are the foundation for school success. Overall, these findings have important implications for understanding the contributions of fathers to their children's language skills and the pathways through which they operate.

\section{Acknowledgements}

We are grateful to the families who participated in this study. This research was partly supported by NIH grant (R03 from NICHD: HD066017) to Natasha Cabrera and Meredith Rowe.

\section{References}

Arriaga, R. I., Fenson, L., Cronan, T., \& Pethick, S. J. (1998). Scores on the MacArthur Communicative Development Inventory of children from low- and middle-income families. Applied Psycholinguistics, 19, 209-223. doi:10.1017/ s0142716400010043

Bagner, D. M., Pettit, J. W., Lewinsohn, P. M., \& Seeley, J. R. (2010). Effect of maternal depression on child behavior: A sensitive period?. Journal of the American Academy of Child and Adolescent Psychiatry, 49(7), 699.

Baron, R. M., \& Kenny, D. A. (1986). The moderatormediator variable distinction in social psychological research: Conceptual, strategic, and statistical considerations. Journal of Personality and Social Psychology, 51(6), 1173.

Boller, K., Bradley, R., Cabrera, N., Raikes, H., Pan, B., Shears, J., \& Roggman, L. A. (2006). The Early Head Start father studies: Design, data collection, and summary of father presence in the lives of infants and toddlers. Parenting, 6(2-3), 117-143.

Bruner, J. (1981). The social context of language acquisition. Language and Communication, 1, 155-178. 
Cabrera, N. J., Hofferth, S., \& Chae, S. (2011). Patterns and predictors of father-infant engagement: Variation by race and ethnicity. Early Childhood Research Quarterly, 26(3), $365-375$

Cabrera, N. J., Shannon, J. D., \& Tamis-LeMonda, C. (2007). Fathers' influence on their children's cognitive and emotional development: From toddlers to pre-K. Applied Developmental Science, 11(4), 208-213.

Cabrera, N. J., Shannon, J. D., Vogel, C., Tamis-Lemonda, C., Ryan, R. M., Brooks-Gunn, J., . . . Cohen, R. (2004). Low-income fathers' involvement in their toddlers' lives: Biological fathers from the Early Head Start Research and Evaluation Study. Fathering: A Journal of Theory, Research, and Practice About Men as Fathers, 2(1), 5-30.

Cummings, E., Keller, P. S., \& Davies, P. T. (2005). Towards a family process model of maternal and paternal depressive symptoms: Exploring multiple relations with child and family functioning. Journal of Child Psychology and Psychiatry, 46(5), 479-489.

Duursma, E., Pan, B. A., \& Raikes, H. (2008). Predictors and outcomes of low-income fathers' reading with their toddlers. Early Childhood Research Quarterly, 23, 351-365. doi:10.1016/j.ecresq.2008.06.001

Ely, R., Gleason, J. B., Narasimhan, B., \& McCabe, A. (1995). Family talk about talk: Mothers lead the way. Discourse Processes, 19, 201-218. doi:10.1080/01638539509544914

Hart, B., \& Risley, T. R. (1995). Meaningful differences in the everyday experience of young American children. Baltimore, MD: Brookes.

Hoff, E. (2003). The specificity of environmental influence: Socioeconomic status affects early vocabulary development via maternal speech. Child Development, 74(5), 1368-1378.

Hoff, E. (2006). How social contexts support and shape language development. Developmental Review, 26(1), 55-88.

Hoff, E., Laursen, B., \& Tardif, T. (2002). Socioeconomic status and parenting. In M. H. Bornstein (Ed.), Handbook of parenting (2nd ed., pp. 231-252). Mahwah, NJ: Lawrence Erlbaum.

MacWhinney, B. (2000). The CHILDES Project: Tools for analyzing talk, Volume II: The database (Vol. 2). Mahwah, NJ: Lawrence Erlbaum.

Mensah, F., \& Kiernan, K. (2010). Parents' mental health and children's cognitive and social development: Families in England in the Millennium Cohort Study. Social Psychiatry and Psychiatric Epidemiology, 45(11), 1023-1035.

Mitchell, S. J., \& Cabrera, N. J. (2009). An exploratory study of fathers' parenting stress and toddlers' social development in low-income African American families. Fathering: A Journal of Theory, Research, and Practice About Men as Fathers, 7(3), 201-225.

Pan, B. A., Rowe, M. L., Spier, E., \& Tamis-LeMonda, C. S. (2004). Measuring productive vocabulary of toddlers in lowincome families: Concurrent and predictive validity of three sources of data. Journal of Child Language, 31(3), 587-608.

Pancsofar, N., \& Vernon-Feagans, L. (2006). Mother and father language input to young children: Contributions to later language development. Journal of Applied Developmental Psychology, 27, 571-587. doi:10.1016/j.appdev.2006.08.003

Pancsofar, N., Vernon-Feagans, L., \& The Family Life Project Investigators. (2010). Fathers' early contributions to children's language development in families from low-income rural communities. Early Childhood Research Quarterly, $25(4), 450-463$.

Paulson, J. F., Keefe, H. A., \& Leiferman, J. A. (2009). Early parental depression and child language development.
The Journal of Child Psychology and Psychiatry, 50(3), 254-262.

Pleck, J. H., \& Masciadrelli, B. P. (2004). Paternal involvement by U.S. residential fathers: Levels, sources, and consequences. In M. E. Lamb (Ed.), The role of the father in child development (4th ed., pp. 222-271). Hoboken, NJ: John Wiley \& Sons.

Radloff, L. S. (1977). The CES-D scale: A self-report depression scale for research in the general population. Applied Psychological Measurement, 1(3), 385-401.

Raikes, H., Luze, G., Brooks-Gunn, J., Raikes, H. A., Pan, B. A., Tamis-LeMonda, C. S., . . . Rodriguez, E. T. (2006). Motherchild book reading in low-income families: Correlates and outcomes during the first three years of life. Child Development, 77(4), 924-953.

Raikes, H. H., \& Love, J. M. (2002). Early Head Start: A dynamic new program for infants and toddlers and their families. Infant Mental Health Journal, 23(1-2), 1-13.

Ramchandani, P., Stein, A., Evans, J., \& O'Connor, T. G. (2005). Paternal depression in the postnatal period and child development: A prospective population study. Obstetrical \& Gynecological Survey, 60(12), 789.

Risley, T. R., \& Hart, B. (2006). Promoting early language development. In N. F. Watt, C. Ayoub, R. H. Bradley, J. E. Puma, W. A. LeBoeuf, N. F. Watt, ... W. A. LeBoeuf (Eds.), The crisis in youth mental health: Critical issues and effective programs, Vol. 4: Early intervention programs and policies (pp. 83-88). Westport, CT: Praeger/Greenwood.

Rodriguez, E. T., \& Tamis-LeMonda, C. (2011). Trajectories of the home learning environment across the first 5 years: Associations with children's vocabulary and literacy skills at prekindergarten. Child Development, 82(4), 1058-1075.

Roopnarine, J. L., Fouts, H. N., Lamb, M. E., \& LewisElligan, T. Y. (2005). Fathers' behaviors toward their 3- to 4-month-old infants in lower, middle, and upper socioeconomic African American families. Developmental Psychology, 41(5), 723-732.

Rowe, M. L., Coker, D., \& Pan, B. A. (2004). A comparison of fathers' and mothers' talk to toddlers in low-income families. Social Development, 13(2), 278-291.

Rowe, M. L., Pan, B., \& Ayoub, C. (2005). Predictors of variation in maternal talk to children: A longitudinal study of low-income families. Parenting: Science and Practice, 5(3), 285-310.

Rowe, M. L., Raudenbush, S. W., \& Goldin-Meadow, S. (2012). The pace of vocabulary growth helps predict later vocabulary skill. Child Development, 83, 508-525. doi:10.1111/j.14678624.2011.01710.x

Tamis-LeMonda, C. S., Cristofaro, T. N., Rodriguez, E. T., \& Bornstein, M. H. (2006). Early language development: Social influences in the first years of life. In L. Balter, C. S. TamisLeMonda, L. Balter, \& C. S. Tamis-LeMonda (Eds.), Child psychology: A handbook of contemporary issues (2nd ed., pp. 79-108). New York, NY: Psychology Press.

Tomasello, M., Conti-Ramsden, G., \& Ewert, B. (1990). Young children's conversations with their mothers and fathersDifferences in breakdown and repair. Journal of Child Language, 17, 115-130.

Vygotsky, L. S. (2000). Mind in society: The development of higher psychological processes. Cambridge, MA: Harvard University Press.

Zimmerman, F. J., \& Katon, W. (2005). Socioeconomic status, depression disparities, and financial strain: What lies behind the income-depression relationship? Health Economics, 14(12), 1197-1215. 